\title{
Swachh Bharath
}

\author{
Rakesh.B, Hemamalini.M, Santhiya.M, Suthendran.K
}

\begin{abstract}
The universe is struggling to survive because of its increasing population. Overpopulation leads to social and environmental problems viz., polluted cities, reduced fresh air (oxygen) and thus results in incalculable diseases and infections. The Indian government has taken initiative to clean up its streets, roads, towns and rural areas through Clean India Mission [1]. However, the result is not appreciable. This work aims to develop mobile application which enables the users/volunteers to report issues through GPS enabled photographs. The administrator will analyze the issue and its location and then reassigns the reported issues to the concerned authorities with priority. After completing the reported issues the GPS enabled picture will be uploaded to the system by concerned authorities to close the issue. Our work removes all the hurdles available in the existing system. The stakeholders finds easy to report, analyze, reassign and track the issues in time.
\end{abstract}

Keywords : Swatchh Campus, Environmental production.

\section{INTRODUCTION}

$\mathrm{T}$ he constant increase in the population is questioning the cleanliness and safety of the city. Cleanliness makes the people to live hygiene life and thus spreading of diseases comes in control. To have hygiene life and environment, the eating water and sanitation comes in to play with above.

The improper sanitation is worsening the environment and easily spreading numerous diseases to all. Mostly, low immune children and elders are becoming victim for this. Often we might have witnessed that overfilled dustbin, blocked drainage on the roads and nearby our living place for a longer time as shown in Figure 1. This is because of the lethargic attitude of government employees. So, many social activists came in to the picture and proposed some useful ideas to the public. In [7], the government has taken initiatives to clean the nation through new schemes. Using android application users can easily register the issues to the concerned.

In 2014, a Swachh Bharat Mission is an awareness campaign launched all over India on the birth date of Mohandas karamchand Gandhi [1][9]. This cleanliness drive was initiated by Ministry of water and sanitation with aim to nullify open defecation by providing facilities for the public.

Revised Manuscript Received on December 16, 2019.

* Correspondence Author

First Author Rakesh B, Information Technology, Kalasalingam Academy of Research and Education, Krishnankoil, India.

Second Author Hemamalini.M, Information Technology, Kalasalingam Academy of Research and Education , Krishnankoil, India

Third Author Santhiya.M, Information Technology, Kalasalingam Academy of Research and Education, Krishnankoil, India

Corresponding Author Suthendran.k*, Information Technology, Kalasalingam Academy of Research and Education , Krishnankoil, India. Email: k.suthendran@klu.ac.in
This drive prevents the ground water pollution mainly. Nullifying air pollution is an each individual responsibility. The author reports that nearly 7 million people die every year because of this pollution [19].

Whatsapp is an interesting mobile application most of them utilizing worldwide for quick communication. Its working principle has attracted many researchers who wish to provide smart and quick solution. In this work, we have proposed an innovative solution to solve above issue based on android mobile application [5].

\section{EXISTING SYSTEM}

The public supposed to approach the corporation personally or through phone call to register a complaint and report a problem there is no prioritization of the grievances received [9]. The processing was done based on the order in which they arrive. This is appreciable. But sometimes, a particular problem may be a serious one, which needs to be addressed immediately. The location of the problematic area was manually specified by the user while reporting the problem which does not ensure $100 \%$ accuracy. Sometimes the unauthorized person may not know the exact location as well. This turns out to be a big disadvantage. So there is a need for a solution which makes job easier.

In today life, each and everyone is busy with their business and none of them are taking care about the happenings in and around them until that hurts them. Though our political system is given options to have representatives for each ward, still many of the issues are unattended. The poor and low immune people are getting affected quickly by this kind of act. Until some chaos happens in the area the residents are not filing complaints to clear bins. The garbage cleaners are working in the main areas of the city and inner area their work is not heartening [10]. So, some strict measures are required to safeguard our nation.

- There is no proper waste disposal

- There is no system to monitor the level of garbage dumps.

- Clearance of garbage is not happening in time.

- Government is not ensuring that each every part of our country is disease and pollution free.

- The public are not educated to use degradable bags and etc.

- Unattended overflowing of wastes [6]. 


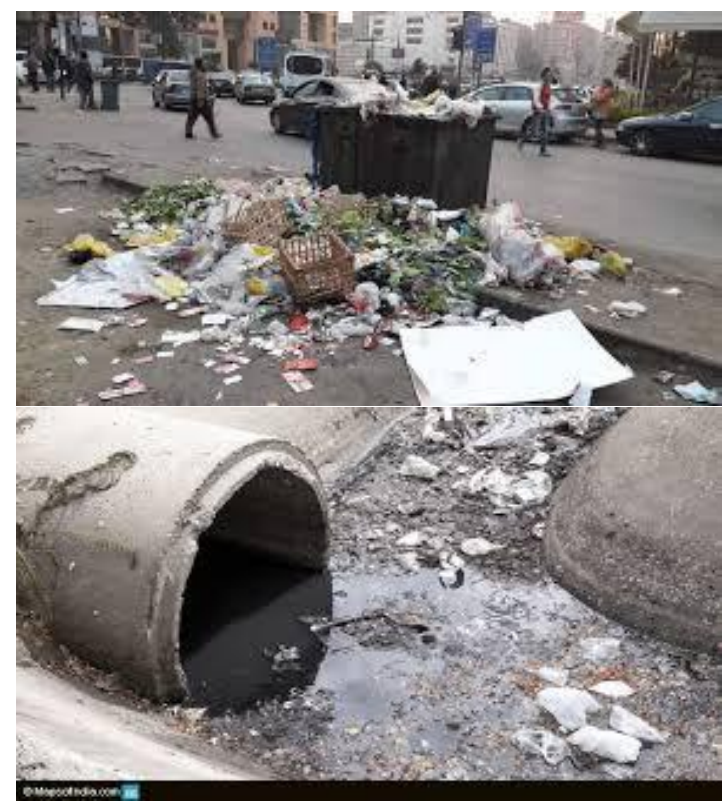

Figure 1.Improper disposal of the garbage

\section{PROPOSED SYSTEM}

In our proposed system, such anomaly can be complained easily just on a single click and the issue reach the concerned department for further actions. The system is implemented at krishnankoil, India.

- The major activities of the system are to receive various types of grievances from people related to our city, facilitate speed processing of grievances received, updating the status of grievances as and when required.

- By using this app, with regard to their own registered complaints about the problems can be monitored.

- The prioritization of the grievances received helps the municipality to decide what problems should be resolved first.

The proposed system makes everyone happy to register a complaint which exists in their way. Since, many of us like taking selfie photos and posting it on social media. Here, we are privileged to utilize that kind of mannerism for complaining an anomaly. So, citizen finds easy to complain such anomaly so the issue is submitted to the government official in time. In turn the officials assign the concerned department people to fix the issue. Because, the status of each complaint can be monitored by every higher officials at all time. This enables ourselves to safeguard our area and wherever we are visiting. Therefore, this application contributes in a great way to achieve our clean India mission. The application provides the following advantages.

- Easy handling.

- Works are carried out in time.

- Hygiene Environment at every nook and corner of our country.

- Prevention of disease spread.

The proposed idea offers smart solution in a cost effective way. The anomaly is fixed as soon as it gets notified to the concern. Therefore, disease spread comes down in to control and thus lead to healthy life.

\section{ANDROID MOBILE APPLICATION}

I Android is a mobile OS first developed by the silicon valley company and named as android it is an open source code, development of android can be done through java, windows, linux and mac instead of allowing java programs to run through the google developed dalvik a virtual machine specifically for android [2].One of the android selling points is to break the application boundaries. These android apps had made a very huge impact in the world. It is mainly designed for smart phones and tablet, and large number of apps are running in this OS[12]. The front end is developed by JAVA, Android Studio 3.3 and for back end SQLite is chosen.

User has to register first before in to the system and report a problem. During the registration process, the user has to provide certain details. Especially specifying the location is very important. The details of the user will be stored in the corresponding database. After registering, the user will have to login with the username and password provided during registration. Each area will have a representative and he/she is responsible for handling the user details and the problems reported by public. [11][13].

In Emergency login user no need to register their details, this login supports the unauthorized users who don't want to trace back the status of reported complaint in future. In other words, when the user finds some anomaly during his/her travel they can utilize this emergency login option without username and password.

The admin will have his/her own unique ID assigned by the officers. He/She should use this ID to provide username and password while registration. He/She uses this username and password to login and carry on his operations. He/She is responsible for the complaints forwarded to him/her, updating the status of the problem to the users.

The user can report a problem using through this application. The problems may include garbage disposal, drainage overflow, pothole on the road, drainage choked/blocked, missing manhole cover and drainage line damaged[3]. The user should have a basic knowledge of using the application. All he needs is a mobile phone, internet and the app installed. Additional features GPS are also needed. Using GPS (Global positioning system), the exaction location of the user is identified by the application which ensures $100 \%$ accuracy. Traditional methods or manual complaints cannot ensure accuracy to this extent. As the mobile phone is portable, exact location can be identified by switching on the GPS which is based on a latitude/longitude-coordinate system [4].

The reported problem will first viewed by the corporation officers by the priority provided. The sanitary officers receives the problem i.e. the problems list contains the username, location, exact location, priority and their statuses. The status can be updated as completed, rejected. As soon as the user login into their accounts, they could see the status updated as completed are rejected. The status will be changed from 'pending image' to 'completed image' when the problem gets solved [14] [18].

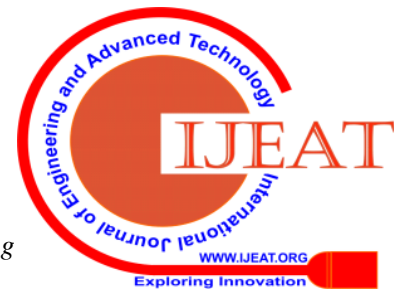


Figure 2 explains the working flow of the proposed system model. From this diagram we can identify how a complaint sends to the authority and how the process is happening [15].

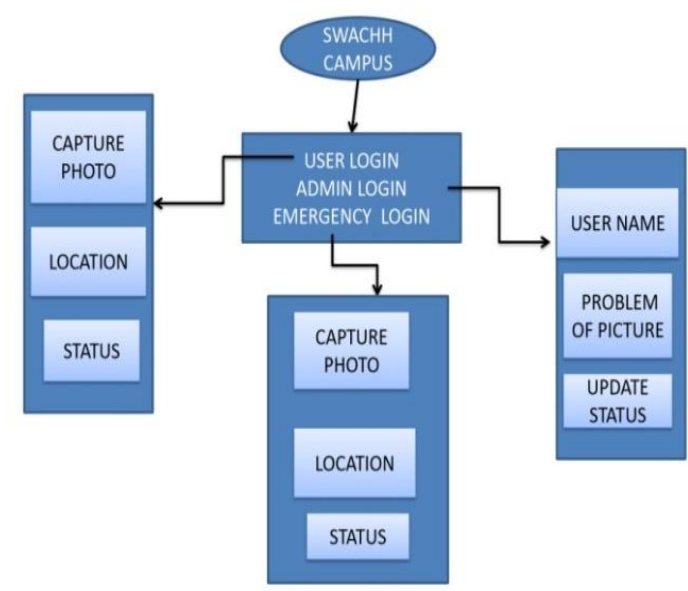

Figure 2.The architecture of the proposed model

The figure 3 . shows the process involved in status generation for the reported issues which is to be executed and implementing the project and know how the status updates were processing and intimating the same to the users.

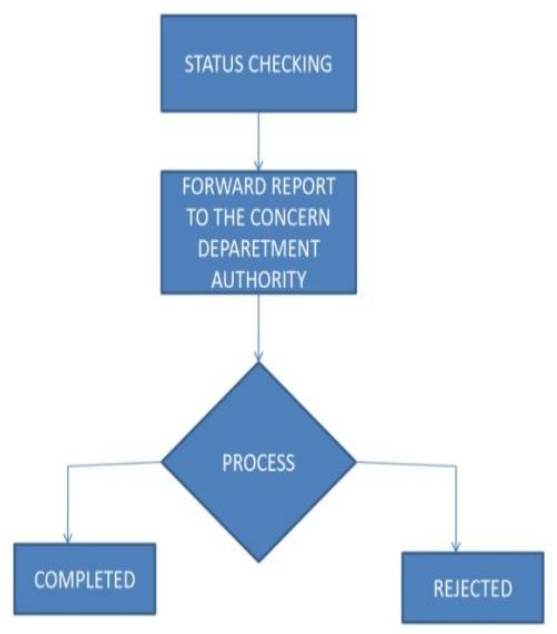

Figure 3.The status generation for end users

\section{EXPERIMENTAL RESULTS}

The Dashboard layout contain completed work view, rejected view, pending images, Capture a image and send to the concern authority and logout option to leave the page as shown in figure. 4

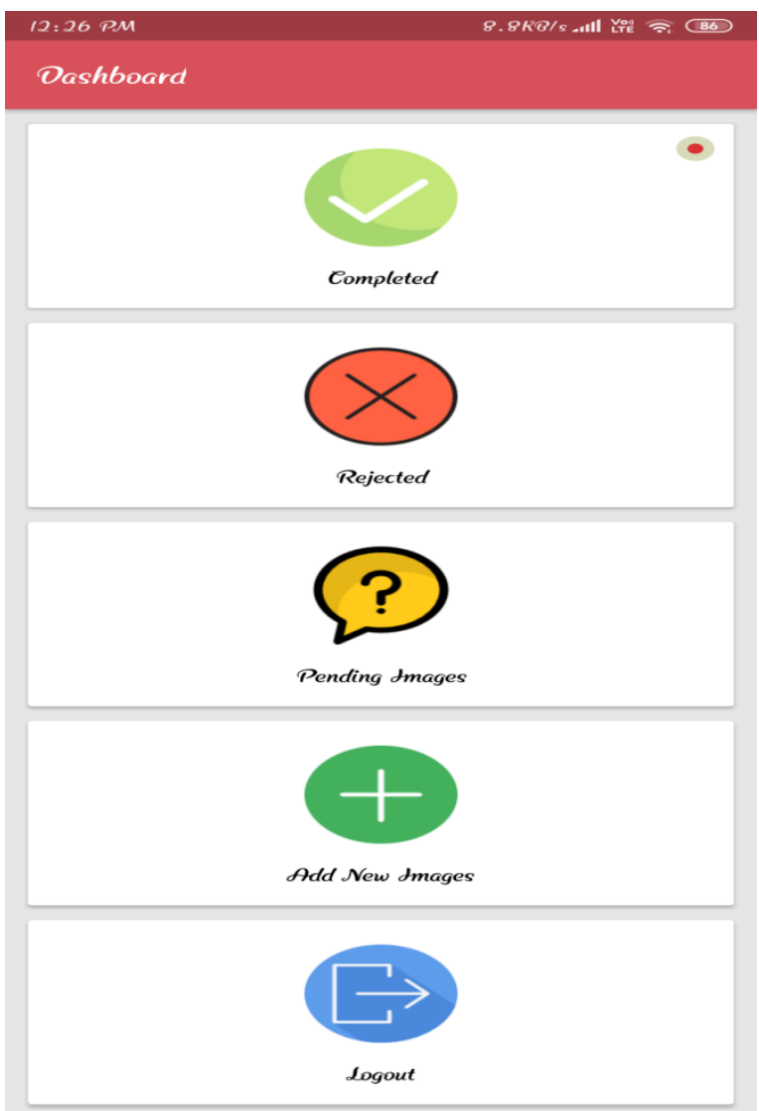

Figure 4. The view of the Mobile Application

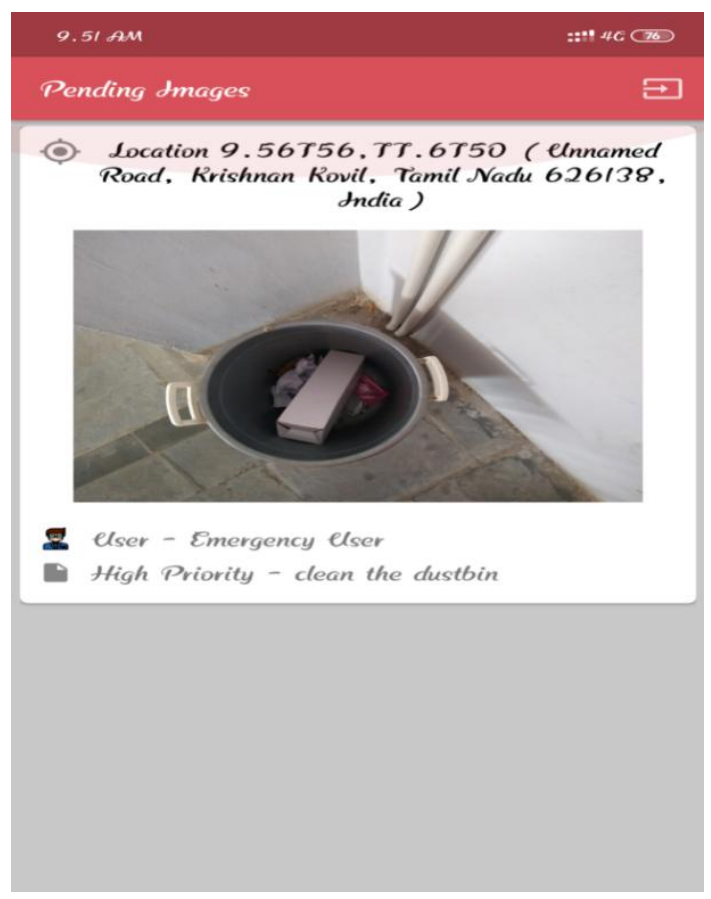

Figure 5. The complained image

Published By: 


\section{Swachh Bharath}

While reporting an anomaly, the photo and its GPS location details are send to the government officials as shown in figure 5. So, by using location details the officials easily identify the spot. The user can also view the pending image which means the complaint filed by the user is not processed or delayed for some valid reason. The user can view pending notification in dashboard.

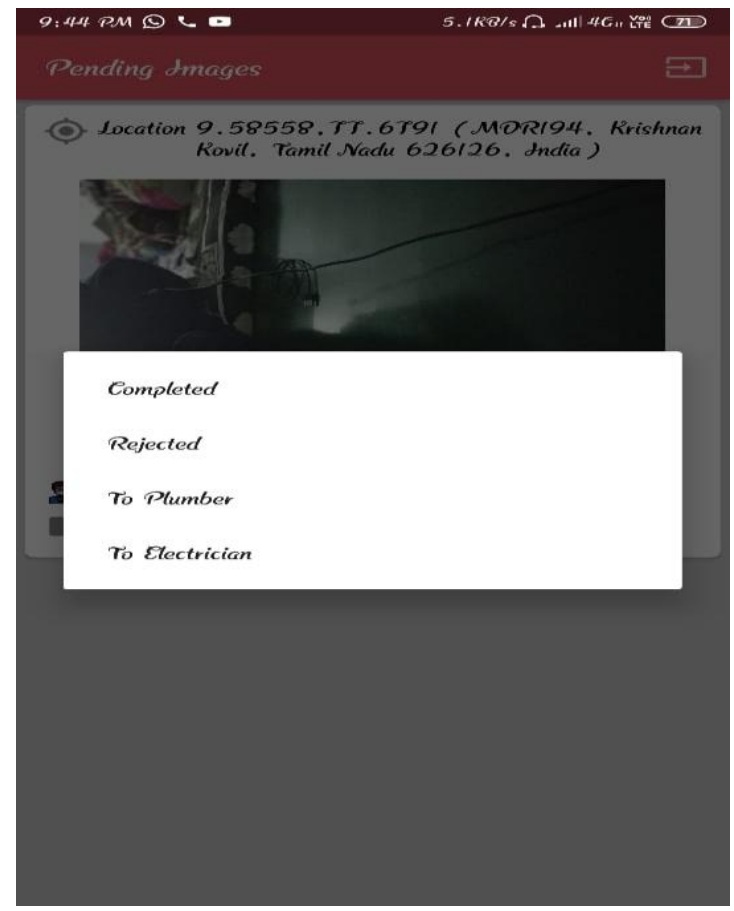

Figure 6. The process of reassigning the complaint

On right clicking the received photo admin have options viz., Completed, Rejected, Plumber, and Electrician. So, the reported issue is assigned to relevant sections [16][17]. The Main admin can view all the problems reported viz., garbage problems sanitation problems and also its updated status in the application. Electrical and plumbing complaints will be solved by the concerned admin and they can also update the status after that

\section{CONCLUSION}

Increase in population has resulted in pollution increase. It is our responsibility to keep our area, city and nation in a hygiene way. The proposed idea was attracted by many people. Many of them are engaging themselves in taking photos with anomaly when they come across and reporting the same. Our imaginative android application supports the nation to achieve this clean India mission. This application makes the government officials in alert mode always because, the status of each report can be monitored by the other higher officials at any point of time.

\section{REFERENCES}

1. Swachh bharat abiyan [https://www.pmindia.gov.in/en/major_initiatives/swachh-bharat-abhiy a]

2. Developers- Android [http://developer. android.coboutlindex.html]

3. Chen Wang, B. David and R. Chalon, "Dynamic Road Lane Management: A smart city application," in Proceedings of International
Conference on Advanced Logistics and Transport (ICALT), pp 72-77,1-3 May, 2014

4. Getting location(latitude and longitude)

[https://androstock.com/tutorials/getting-current-location-latitude-longi tude-country-android-android-studio.html]

5. https://developer.android.com/training/basics/firstapp

6. Naveen K R \& Nandini Hampole, "Swacha Bangalore: A New Way Of.Managing Waste In Urban Areas," CCS Research Internship Papers, Centre for Civil Society, India, 2004.

7. https://en.wikipedia.org/wiki/Nirmal_Bharat_Abhiyan

8. https://en.wikipedia.org/wiki/Swachh_Bharat_Abhiyan

9. Elizabeth Shove, Comfort, Cleanliness, and Convenience: The Social Organization of Normality (Berg, 2003), p. 80.

10. Jacob Burckhardt, The Civilization of the Renaissance in Italy, as quoted by Douglas Blow, The Culture of Cleanliness in Renaissance Italy (Cornell University Press, 2006).

11. Bombay Sarvodaya Mandal \& Gandhi Research Foundation, Importance of Gandhian thoughts about Cleanliness - By Dr. Shubhangi Rathi. O. Young, "Synthetic structure of industrial plastics (Book style with paper title and editor)," in Plastics, 2nd ed. vol. 3, J. Peters, Ed. New York: McGraw-Hill, 1964, pp. 15-64.

12. Umesh IsalkarUmesh Isalkar, TNN (30 April 2013). "Census raises stink over manual scavenging". The Times of India. Retrieved 6 September 2015

13. "Manual scavenging still a reality". The Hindu. 9 July 2015. Retrieved 9 September 2015.

14. Improving Consumer Voices and Accountability in the Swachh Bharat Mission, Public Affairs Centre National Policy Review (Revised) 2015-16

15. Study on Perception and Practice of Hygiene and impact on health in India Kumar Jyoti Nath, Barenyo Chowdhury, Anish Sengupta [India]

16. S Rajeswari, "An Overview of the MapReduce Model", International Conference on Theoretical Computer Science and Discrete Mathematics,Springer,pp. 312-317,2016.

17. Fepslin Athish Mon, "Group Communication Management in UAVMBN Networks", International Journal of Pure and Applied Mathematics,Vol.118,pp. 349-355, 2018.

18. T Ramu, "Machine learning based soft biometrics for enhanced keystroke recognition system", Multimedia Tools and Applications,pp. 1-17,2019.

19. "UNDP- Jharkhand: Economic and Human Development Indicators" http://www.in.undp.org. 